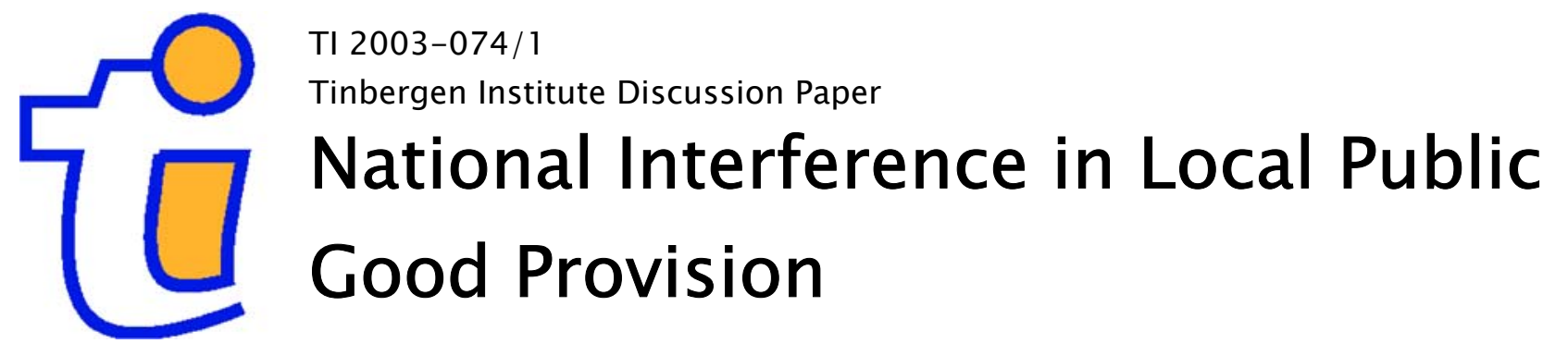

Robert Dur*

Klaas Staal

Faculty of Economics, Erasmus University Rotterdam, and Tinbergen Institute.

*CESifo, Munich. 


\section{Tinbergen Institute}

The Tinbergen Institute is the institute for economic research of the Erasmus Universiteit Rotterdam, Universiteit van Amsterdam, and Vrije Universiteit Amsterdam.

Tinbergen Institute Amsterdam

Roetersstraat 31

1018 WB Amsterdam

The Netherlands

Tel.: $\quad+31(0) 205513500$

Fax: $\quad+31(0) 205513555$

Tinbergen Institute Rotterdam

Burg. Oudlaan 50

3062 PA Rotterdam

The Netherlands

Tel.: $\quad+31(0) 104088900$

Fax: $\quad+31(0) 104089031$

Please send questions and/or remarks of nonscientific nature to driessen@tinbergen.nl.

Most TI discussion papers can be downloaded at http://www.tinbergen.nl. 


\title{
National Interference in Local Public Good Provision
}

\author{
Robert Dur* Klaas Staal ${ }^{\dagger}$
}

September 18, 2003

\begin{abstract}
We analyze a simple model of local public good provision in a country consisting of a large number of heterogeneous regions, each comprising two districts, a city and a village. When districts remain autonomous and local public goods have positive spillover effects on the neighbouring district, there is underprovision of public goods in both the city and the village. When districts unite, underprovision persists in the village (and may even become more severe), whereas overprovision of public goods arises in the city as urbanites use their political power to exploit the villagers. From a social welfare point of view, inhabitants of the village have insufficient incentives to vote for unification. We examine how national transfers to local governments can resolve these problems.
\end{abstract}

Keywords: local public goods, municipal consolidation, voting, intergovernmental transfers.

JEL codes: D7, H2, H7, R5.

*Tinbergen Institute, Erasmus University Rotterdam, and CESifo, Munich. Address: Department of Economics H 7-21, P.O. Box 1738, 3000 DR Rotterdam, The Netherlands. E-mail: dur@few.eur.nl, Phone: +31104082159, Fax: +31104089147.

†Tinbergen Institute, Erasmus University Rotterdam. E-mail: staal@few.eur.nl. 


\section{Introduction}

Inhabitants of villages that are located close by a city usually benefit considerably from the services provided by the city. Many villagers work in the city. Moreover, they often find the city a good place to spend their leisure time. In as far as public services are concerned, the costs of services provided by the city are commonly completely borne by the inhabitants of the city. As inhabitants of cities usually benefit to a much smaller extent from the services provided in villages than villagers benefit from cities' services, representatives of cities have claimed that the distribution of the tax burden is unfair. Moreover, the interjurisdictional spillover effects of public good provision may give rise to severe underprovision as voters in the city do not take into account the benefits of the city's public good provision on the welfare of the villagers. The same holds for the public good provision in the village in as far as urbanites benefit from public good provision in the village.

A natural policy response to these problems is to unify cities and villages. Unsurprisingly, inhabitants of villages often fiercely oppose unification as it entails a large tax increase. Villagers claim that the only goal of unification is to relieve the financial problems of the city. Moreover, they fear that their interests will be ignored because they constitute a minority in political decision-making bodies after unification. Consequently, public good provision in the village may be reduced. When villagers have the right to decide on whether to unite with a city or not, unification will therefore be a rare event.

This paper studies how national transfers to local governments can resolve these problems. We analyze a simple model of local public good provision in a country consisting of a large number of heterogeneous regions. Each region consists of two districts that differ in size, a city and a village. The city and the village either form one municipality or they remain autonomous. We assume that unification requires the consent of a majority of voters in both the city and in the village. In line with earlier studies, we find that when districts remain autonomous, there is underprovision of local public goods in both districts. Underprovision of public goods in the village persists after unification, and may even become more severe. In the city, unification results in overprovision of public goods, as the urbanites start exploiting the villagers. Lastly, our model implies that from a social welfare point of view, voters in the village have insufficient incentives to vote for unification.

We consider the effects of two types of national transfers: an earmarked transfer that increases with local public good provision and a lump-sum transfer to municipalities that is independent of population size. An earmarked subsidy helps to mitigate the underprovision problem. A lump-sum tax strengthens the incentives for unification. Heterogeneity between regions causes neither of these transfers to attain the first-best. Earmarked transfers promote welfare as they increase public goods provision in autonomous districts, but exacerbate the problem of 
overprovision of public goods in cities that merged with a village. Moreover, even when all districts remain autonomous, differences in the size of the spillover effect between regions cause earmarked transfers to result in overprovision in some regions, while underprovision persists in other regions. A lump-sum tax that is independent of population size promotes unification in regions where it is socially desirable, but also in regions where districts can better remain autonomous. The optimal lump-sum transfer as well as the optimal earmarked transfer entail a trade off between these desired and undesired effects and crucially depend on the exact distribution of relative population sizes and spillover effects over regions.

Transfers from national governments to local governments are widespread. For instance, in The Netherlands, about $7 \%$ of the national government budget is transferred to local governments through the 'Gemeentefonds'. Parts of these transfers are earmarked. In Germany, the 'Gemeindefinanzierungsgesetz' arranges the transfers from the 'Länder' to the 'Kommunen'. In Sweden, local governments receive general grants and equalization grants from the 'staten'. In the US, towns receive intergovernmental grants from the federal government, from the state, and from the county.

The economics literature gives little attention to the effect of transfers on incentives for unification. ${ }^{1}$ One reason is that most papers on political geography focus on formation of countries rather than on unification of local jurisdictions. Related to the present paper are Alesina and Spolaore (1997), Bolton and Roland (1996, 1997), and Goyal and Staal (2003). ${ }^{2}$ In contrast to the present analysis, these papers assume that centralized policy is uniform. Our set-up is close to Besley and Coate (1999), who study the merits of centralized provision of local public goods when provision need not be uniform across jurisdictions. The main differences between our paper and theirs is that we endogenize the decision on centralization and that we allow for transfers from a higher-level government.

Three other papers are close to our analysis. First, Calabrese, Cassidy, and Epple (2002) develop a computational model to study the effects of and political support for municipal consolidation. Their main focus is on local redistributive policies and housing prices. Ellingsen (1998) studies the effects of inter- and intraregional heterogeneity in preferences and the relative size of regions on political integration. Heterogeneity in preferences between regions also plays a key role in Lockwood (2002). None of these papers examines the role of transfers from a national government.

The paper is organized as follows. Section 2 presents the basic model. Next, in section 3.1, we derive the socially optimal amounts of local public goods. Section 3.2 examines the outcome of voting on public good provision, when districts are

\footnotetext{
${ }^{1}$ There is, however, a large literature on intergovernmental transfers where jurisdictional boundaries are taken as given, most prominently Oates (1972), Gordon (1983), Persson and Tabellini (1996), and Dixit and Londregan (1998). For a survey, see Oates (1999).

${ }^{2}$ For a survey of the literature on the size of countries, see Bolton, Roland and Spolaore (1996).
} 
autonomous and when they are united. Section 3.3 derives the conditions under which districts decide to unite. In section 3.4, these conditions are compared with the conditions for socially optimal unification. Section 4 examines the effects of national transfers to municipalities. Section 5 concludes.

\section{The model}

Consider a country consisting of many regions. Each region consists of two districts (cities, villages). Districts in a region differ from each other in population size; otherwise they are identical. The population size of district $i$ in region $j$ is denoted by $\alpha_{i j}$. Inhabitants of a district are homogenous and immobile.

Districts in a region either form one municipality or two separate municipalities. Forming one municipality requires majority support in each of the districts. A municipality is responsible for the provision of local pure public goods. Decisions on public goods provision are taken by majority rule. The amount of public goods provided in district $i$ in region $j$ is denoted by $g_{i j}$. Public goods provided in a district have positive spillover effects on the other district in the region. The utility function of an inhabitant of district $i$ in region $j$ is:

$$
U_{i j}=\sqrt{g_{i j}}+\kappa \sqrt{g_{-i j}}+y-t_{i j}
$$

where $g_{-i j}$ is the amount of public goods provided in the other district in region $j$, the parameter $\kappa \in[0,1]$ measures the degree of spillovers, $y$ is before-tax private income per capita, and $t_{i j}$ is a local lump-sum tax. Note that we abstract from income heterogeneity. Further, we assume that public goods and private goods are separable in the utility function and that taxes are nondistortionary. A convenient implication is that we can omit $y$. We will discuss some of the consequences of these assumptions along the way and in the concluding section.

The cost of a public good is equal to $p$ units of private goods. Public goods are financed by local lump-sum taxes, $t_{i j}$, and by transfers from the central government to the local governments, $f(\cdot)$. The latter may depend on, e.g., the population size of the municipality and on the amount of public goods provided. If districts in region $j$ are two separate municipalities, the local government's budget constraint reads:

$$
p g_{i j}=f(\cdot)+t_{i j} \alpha_{i j}
$$

If districts in region $j$ form one municipality, the budget constraint is:

$$
p\left(g_{i j}+g_{-i j}\right)=f(\cdot)+t_{j}\left(\alpha_{i j}+\alpha_{-i j}\right)
$$

Note that we impose the condition that the per capita taxes within a municipality are uniform across districts. 


\section{Local public good provision and unification of municipalities}

We structure our analysis as follows. First, we derive the socially optimal levels of local public goods. Next, we analyze political decision making and contrast the outcomes with the normative benchmark. The political decision making process consists of two stages. First, voters in each district vote on whether to unite with the neighboring district into one municipality or to remain autonomous. Next, there is a vote on the amount(s) of public goods in each municipality. For the moment, we abstract from central funding, $f(\cdot)=0$. In section 4 , we study national transfers aimed at improving the allocative efficiency of local public good provision in heterogenous regions. Since we abstract from interregional spillovers, and inhabitants are immobile, we restrict attention in this section to public goods provision and unification of municipalities in a particular region. For convenience, we drop the subscript $j$, and we denote the larger district in the region as the city $(c)$ and the smaller district as the village $(v), \alpha_{c}>\alpha_{v}$.

\subsection{Social optimum}

We define the social optimum as the outcome that maximizes the unweighted sum of utilities of all individuals in the region:

$$
\max _{g_{c}, g_{v}} \alpha_{c}\left(\sqrt{g_{c}}+\kappa \sqrt{g_{v}}\right)+\alpha_{v}\left(\sqrt{g_{v}}+\kappa \sqrt{g_{c}}\right)-p g_{c}-p g_{v}
$$

The social surplus maximizing public good levels $\left(g_{c}^{s}, g_{v}^{s}\right)$ that result from this optimization problem are:

$$
\begin{aligned}
& g_{c}^{s}=\left(\frac{\alpha_{c}+\kappa \alpha_{v}}{2 p}\right)^{2} \\
& g_{v}^{s}=\left(\frac{\alpha_{v}+\kappa \alpha_{c}}{2 p}\right)^{2}
\end{aligned}
$$

Hence, the socially optimal amount of public goods in each district increases in the population size of both districts, increases in the size of the spillover effect, and decreases in the cost of public goods provision.

\subsection{Voting on public goods provision}

First consider the case where districts remain autonomous. Recall that voters are homogenous within districts. Hence, the outcome of voting in district $i$ is found by maximizing (1) with respect to $g_{i}$ subject to the budget constraint (2). The 
equilibrium levels of public goods $\left(g_{c}^{a}, g_{v}^{a}\right)$ are:

$$
\begin{aligned}
& g_{c}^{a}=\left(\frac{\alpha_{c}}{2 p}\right)^{2} \\
& g_{v}^{a}=\left(\frac{\alpha_{v}}{2 p}\right)^{2}
\end{aligned}
$$

Clearly, local public goods are underprovided when districts are autonomous [compare (7) and (8) with (5) and (6), respectively]. The reason is that voters in each district do not take into account the positive spillover effect of public goods on welfare in the other district. Underprovision is more severe for larger spillover effects and for a larger population size of the neighboring district.

When districts unite into one municipality, the inhabitants of the city are in a majority and, therefore, $g_{c}$ and $g_{v}$ are set according to their wishes. Maximizing (1) with respect to $g_{c}$ and $g_{v}$ subject to the budget constraint (3) results in:

$$
\begin{aligned}
& g_{c}^{u}=\left(\frac{\alpha_{c}+\alpha_{v}}{2 p}\right)^{2} \\
& g_{v}^{u}=\left(\frac{\kappa\left(\alpha_{c}+\alpha_{v}\right)}{2 p}\right)^{2}
\end{aligned}
$$

Unification results in overprovision of public goods in the city, whereas underprovision of public goods in the village persists and may become even more severe than under autonomy [compare (9) and (10) with (5) and (6) and with (7) and (8), respectively]. The intuition is clear. Unification broadens the tax base. Hence, the per capita tax per unit of public good is lower. This induces inhabitants of the city (the decisive voters) to increase the amount of public goods provided in their district. Since they do not take into account the tax cost to the inhabitants of the village, and the villagers benefit less from public goods provided in the city than the urbanites, public goods provision in the city is higher than socially optimal. The effect of unification on the amount of public goods provided in the village is ambiguous. On the one hand, the per capita tax per unit of public good decreases, resulting in an increase in the amount of public goods provided. This effect is larger for a larger population size of the city. On the other hand, it is the urbanites, not the villagers, who decide on public goods provision after unification. This reduces the amount of public goods provided in the village as urbanites care less about the public goods in the village than do the villagers. This effect is larger for a smaller spillover effect. Comparing (10) with (8), it follows that unification increases public goods supply in the village if $\kappa>\frac{\alpha_{v}}{\alpha_{c}+\alpha_{v}}$. Hence, public goods supply in the village increases if the spillover effect or the relative population size of the city is sufficiently large. Since $\alpha_{v}<\alpha_{c}, \kappa \geq \frac{1}{2}$ is a sufficient condition. In all cases, underprovision of public goods persists in the village as inhabitants of the city care less than the inhabitants of the village about public goods supply in the village [compare (10) with (6)]. 
Lastly, it is easily verified that the per capita tax is always higher when districts unite than when they remain autonomous and - in the latter case - that the tax in the city is higher than the tax in the village:

$$
t_{v}^{u}=t_{c}^{u}=\left(1+\kappa^{2}\right) \frac{\alpha_{c}+\alpha_{v}}{4 p}>t_{c}^{a}=\frac{\alpha_{c}}{4 p}>t_{v}^{a}=\frac{\alpha_{v}}{4 p}
$$

Clearly, when public and private goods would not be separable in the utility function, this need not be the case because income effects come into play.

\subsection{Voting on unification of municipalities}

In each district, there is a vote on whether to unite with the neighboring district into one municipality or to remain autonomous. Using the results from the previous subsection, urbanites favor unification if:

$$
\left(1+\kappa^{2}\right) \frac{\alpha_{c}+\alpha_{v}}{2 p}>\frac{\alpha_{c}}{4 p}+\kappa \frac{\alpha_{v}}{2 p}
$$

Unsurprisingly, this condition is always satisfied. Unification benefits the inhabitants of the city as it brings about a broader tax base and the right to decide on the level of $g_{v}$. Villagers favor unification if:

$$
\left(4 \kappa-\kappa^{2}-1\right) \frac{\alpha_{c}+\alpha_{v}}{4 p}>\frac{\alpha_{v}}{4 p}+\kappa \frac{\alpha_{c}}{2 p}
$$

Rewriting yields:

$$
\left(4 \kappa-\kappa^{2}-2\right) \alpha_{v}>\left(1+\kappa^{2}-2 \kappa\right) \alpha_{c}
$$

The right-hand side is positive for all values of $\kappa$ between zero and unity. The left-hand side is negative when $\kappa \in[0,2-\sqrt{2})$. Hence, when the spillover effect is small, villagers oppose unification for any values of $\alpha_{v}$ and $\alpha_{c}$. For $\kappa>2-\sqrt{2}$, we can write the condition as:

$$
\frac{\alpha_{v}}{\alpha_{c}}>\frac{1+\kappa^{2}-2 \kappa}{4 \kappa-\kappa^{2}-2}
$$

This condition is depicted in Figure 1.

[FIGURE 1]

Unification can only be in the villager's interest if $\kappa>3 / 2-\frac{1}{2} \sqrt{3}$. The villagers' incentive to unite becomes stronger as the spillover effect is larger. The intuition is clear. After unification, public goods provision reflects the wishes of the urbanites. When spillovers are small, unification reduces the level of public goods that are provided in the village while the tax burden increases as villagers now have to pay for the public goods provided in the city. In addition, when spillovers are small, villagers benefit little from the increase in public goods supply in the city. When spillovers are larger, unification may increase public goods 
provision in the village and villagers benefit to a larger extent from the increase in public goods provision in the city. If spillovers are sufficiently large, the welfare gain from the increase in public goods compensates for the increase in the tax.

More surprisingly, provided that $\kappa>2-\sqrt{2}$, the incentive to unite increases in the relative size of the village, while the reverse holds when $\kappa<2-\sqrt{2}$. Two effects, working in opposite directions, play a role.

First, the villagers must pay for the public goods that are provided in the city when they decide to unite, while they can free ride on the city's tax payers when they remain autonomous. The larger is the city's population size, the larger is the tax increase for the villagers. A larger population size in the city thus weakens the incentive to unite. Unification, however, also increases the amount of public goods provided in the city as it broadens the tax base. This effect increases in the population size of the village. If $\kappa<\frac{1}{2}$, the positive effect of higher public good provision in the city on villagers' utility does not compensate for the accompanied increase in the tax burden. Then, a larger population size in the village reduces the incentive to unite. If $\kappa>\frac{1}{2}$, the villagers' benefit from increased public good provision in the city is larger than the utility loss from the tax increase. Then, a larger population size in the village makes it more likely that villagers support unification.

Second, for any value of $\kappa$, a higher population size in the city promotes unification as it becomes more likely that public goods provision in the village increases. In contrast, the more populous the village, the weaker the incentive to unite. When the village is large, the level of public goods under autonomy is already high and, hence, it becomes less likely that unification results in an increase in public goods provision in the village.

Taking the two effects together, it follows that the incentive to unite decreases in the relative size of the village when spillovers are small $(\kappa<2-\sqrt{2})$, while the reverse holds when spillovers are large $(\kappa>2-\sqrt{2})$.

\subsection{Socially optimal unification}

Unification is only in the villagers' interest when spillovers are large and the village is not too small relative to the city. An important question is under what conditions unification brings us closer to the social optimum. In other words, do villagers have sufficient incentives to vote for unification from a social welfare point of view? Comparing social welfare under autonomy and unification, we find that unification raises welfare if:

$$
\alpha_{v}^{2}\left(2-4 \kappa+\kappa^{2}\right)-\kappa^{2} \alpha_{c}^{2}<0
$$

When $\kappa>2-\sqrt{2}$, the first term is negative and, hence, unification always increases social welfare. When $\kappa<2-\sqrt{2}$, we can write the condition as:

$$
\frac{\alpha_{v}}{\alpha_{c}}<\frac{\kappa}{\sqrt{2-4 \kappa+\kappa^{2}}}
$$


This condition is depicted in Figure 2, together with the political feasibility constraint which we derived in the previous section.

[FIGURE 2]

Unification increases welfare if the spillover effect is sufficiently large. If $\kappa>\frac{1}{2}$, unification always increases welfare. A large spillover effect implies that underprovision is severe under autonomy and makes it more likely that public goods supply in both the city and the village increase after unification. When the spillover effect is small, unification only increases aggregate welfare if the village is small relative to the city. The intuition is straightforward. The smaller the village, the smaller the increase in the tax base, and hence the less severe the overprovision of public goods in the city after unification. Moreover, when the village is small relative to the city, it is more likely that unification increases public good provision in the village, and hence partly resolves the underprovision problem in the village. Clearly, villagers' incentives to vote for unification are insufficient from a social welfare point of view. The reason is that they do not take into account the effect of unification on the welfare of the urbanites.

\section{National government}

The previous section showed that: i) autonomous districts underprovide public goods; ii) unification does not solve (may even worsen) the problem of underprovision in the smallest district and results in overprovision in the largest district; iii) voters in the smallest district have insufficient incentives to vote for unification from a social welfare point of view. This section examines how the national government may improve upon the decentralized equilibrium outcome by conditioning national transfers to municipalities on local characteristics. We assume that the national government can condition transfers to municipalities on population size and on the levels of public goods that are provided. The national government does not observe the size of the spillover effect in different regions. If it could condition transfers also on the size of the spillover effect, the national government could generate any level of public good provision (including first-best provision in all districts) without creating any distortions. We feel that it is plausible to assume that the national government lacks information about spillover effects in different regions. We analyze the effects of two types of transfers: i) a transfer that is conditional on the level of public goods and that must be spent on public goods (earmarked transfers) and ii) a lump-sum transfer per municipality. The earmarked transfer helps mitigating the underprovision problem. The lump-sum transfer affects the incentives for unification and may thus indirectly increase the allocative efficiency of public goods provision in the economy. 


\subsection{Earmarked transfer}

The national government gives a transfer of $\sigma$ per unit of public good provided in each municipality. The transfer is earmarked: it must be spent on the same public good that it is conditioned on. The national government finances the subsidy to local public good provision by means of a national income tax. We assume that the number of municipalities is sufficiently large, such that a single municipality's decisions have a negligible effect on the national tax rate. Hence, we can safely ignore the national tax in the analysis of local public goods provision and unification of municipalities.

First consider autonomous districts. Maximizing (1) with respect to $g_{i}$, subject to the budget constraint (2), and recognizing that each unit of $g_{i}$ delivers $(1+\sigma) g_{i}$ through the transfer scheme, results in the equilibrium level of public goods provision:

$$
g_{i}^{a}=\left(\frac{(1+\sigma) \alpha_{i}}{2 p}\right)^{2}
$$

Comparing (7) with (14), it follows that the level of public goods increases in the earmarked transfer. Similarly, when districts unite, public goods provision in equilibrium is:

$$
\begin{aligned}
& g_{c}^{u}=\left(\frac{(1+\sigma)\left(\alpha_{c}+\alpha_{v}\right)}{2 p}\right)^{2} \\
& g_{v}^{u}=\left(\frac{(1+\sigma) \kappa_{j}\left(\alpha_{c}+\alpha_{v}\right)}{2 p}\right)^{2}
\end{aligned}
$$

It is easily verified that the earmarked transfer does not affect the incentives to unite. The reason is that the transfer $\sigma$ increases welfare under the different regimes equiproportionally. For the same reason, the condition under which unification is socially optimal is not affected by the level of the earmarked transfer.

Earmarked transfers do not bring about socially optimal public goods provision for at least two reasons. First, in regions where districts have merged, earmarked transfers aggravate the problem of overprovision of public goods in the largest district. Second, when spillover effects differ between regions, a given level of $\sigma$ is too low in some regions, while it is too high in others. Hence, underprovision will persist in some regions, while earmarked transfers cause overprovision in other regions. ${ }^{3}$ The optimal level of $\sigma$ will crucially depend on the exact distribution of $\kappa_{j}$ 's over regions as well as on the distribution of $\frac{\alpha_{v}}{\alpha_{c}}$ over regions.

\footnotetext{
${ }^{3}$ Conditioning $\sigma$ on the population size of municipalities may help, but does not eliminate these problems because of the differences in $\kappa$ between regions.
} 


\subsection{Lump-sum transfer}

Another, less direct way to enhance allocative efficiency of public goods provision is to promote unification of districts. As we saw in the previous section, the villagers have insufficient incentive to unite from a social welfare point of view. A simple way to strengthen the incentives to unite is to make a lump-sum transfer. ${ }^{4}$ Suppose the national government provides a lump-sum transfer $\mu$ to each municipality. Villagers favor unification if:

$$
\left(4 \kappa_{j}-\kappa_{j}^{2}-1\right) \frac{\alpha_{c}+\alpha_{v}}{4 p}+\frac{\mu}{\alpha_{c}+\alpha_{v}}>\frac{\alpha_{v}}{4 p}+\kappa_{j} \frac{\alpha_{c}}{2 p}+\frac{\mu}{\alpha_{v}}
$$

Clearly, $\mu<0$ promotes unification. A lump-sum tax which is equal for all municipalities makes it more likely that villagers support unification as unification enables them to share the tax with more people. Just like the earmarked transfer, the lump-sum transfer is not a distortion-free instrument. Since the national government does not observe $\kappa_{j}$, the lump-sum tax is either too low to induce unification in all cases in which unification is socially desirable, and/or the lumpsum tax is so high that some small villages have an incentive to unite while it would be socially optimal to remain autonomous. The optimal lump-sum transfer entails a trade off between these two effects and will crucially depend on the exact distribution of $\kappa_{j}$ over regions.

\section{Concluding remarks}

In this paper we presented a model to study local public goods provision, endogenous formation of municipalities, and the effects of transfers from higher-level governments. A well-known result is that decentralized public good provision leads to underprovision when there are positive spillovers. We have shown that centralized public good provision may lead to overprovision of local public goods in the largest district. Moreover, when the spillover benefits are small, centralized provision may aggravate underprovision in the smallest district. As a rule, there are insufficient incentives for unification in the smallest district. A national government can alleviate above-mentioned problems by implementing a transfer scheme. We have considered an earmarked transfer, acting upon the amounts of local public goods provided, and a lump-sum transfer, affecting the incentives

\footnotetext{
${ }^{4}$ There exist more sophisticated transfer schemes to manipulate the incentives to unite, where the transfers depend on the (relative) size of the village. Given that $\kappa$ is not observed by the national government, none of them will bring about the social optimum, however. As for the earmarked transfer, the optimal scheme is dependent of the exact distribution of $\kappa$ over regions. We have attempted to derive optimal transfer schemes for specific distributions, but we either failed to obtain a solution or felt that the solution did not bring much additional insights.
} 
for unification. When the national government is not fully informed about local preferences, these transfers do not bring about the social optimum. Optimal transfers depend crucially on the distribution of spillover effects over regions.

Our analysis can be extended in several important ways. Firstly, one could drop the assumption that individuals are immobile, and introduce a housing market, as in Calabrese, Cassidy, and Epple (2002). When mobility is costless, housing prices in market equilibrium will be such that the utility of urbanites and citizens is equal. The welfare effects of unification of the city and the village will then be reflected in a change in relative housing prices. We conjecture that our main results will still hold after this modification. A nice feature of this extension is that it could yield hypotheses that can be empirically tested using housing prices before and after unification of municipalities.

Secondly, a threat of secession and the possibility of bargaining between the municipalities could be introduced in the model. Before unification, the urbanites and villagers could attempt to agree upon levels of taxation and public goods provision, which can be different from the unrestricted majority voting outcome. Compliance might be enforced by the threat of secession by one of the districts. ${ }^{5}$ It is clear that bargaining would make unification politically feasible for most, if not all, of the cases where unification is socially optimal. In fact, there would be no need to unify municipalities, coordinating public good supply would suffice. As Inman and Rubinfeld (1997) note and anecdotical evidence suggests, however, the overall record of 'cooperative federalism' has not been impressive.

Thirdly, we have restricted our analysis to the issue of what would be a socially optimal transfer scheme. Obviously, policy makers at the central level who deicide on the transfers may have other interests, either because they represent mainly urbanites (or villagers), or because they are responsive to lobbying efforts by local governments, as in Borck and Owings (2003), or because they can use intergovernmental grants to win votes in districts with many swing voters, as in Johansson (1999). It would be interesting to examine the interplay between political decision making at the central level and at the local level, taking into account the inefficiencies in local political decision making that we identified in this paper. Likewise, politicians and voters at the local level may have other motives for unification than those stressed in our paper. Austin (1999) shows that the current decisive voter may support unification so as to influence the indentity of the decisive voter in the future. His empirical analysis suggests that these political motives may be more important than economic motives. Filer and Kenny (1980), on the other hand, do find evidence that voters vote in line with their dollar benefits of unification.

Lastly, the model could be extended so as to capture a number of other features that appear to be important in political decision making on unification of

\footnotetext{
${ }^{5}$ Le Breton and Weber (2001) have recently developed a model where transfers are used to prevent secession by regions.
} 
municipalities and local public good provision, like asymmetric spillovers (urbanites usually benefit less from public goods provision in the village than villagers benefit from the city's public goods), income heterogeneity, and economies of scale in public good production. While the latter may imply that inhabitants of small villages are more favorable to unification than suggested by our analysis, the former two tend to strengthen the villager's opposition.

\section{Acknowledgements}

We thank Ami Glazer, Sanjeev Goyal, Henrik Jordahl, Otto Swank, and participants at presentations in Aarhus Universitet (2003 Annual Meeting of the European Public Choice Society), Erasmus Universiteit Rotterdam, and Duke University (Public Economic Theory 2003 Meeting) for useful comments. Dur gratefully acknowledges financial support from NWO, KNAW, and VSNU through a Vernieuwingsimpuls grant. Staal thanks Vereniging Trustfonds Erasmus Universiteit Rotterdam for financial assistance.

\section{References}

[1] Alesina, A. and E. Spolaore (1997), On the number and size of nations, Quarterly Journal of Economics, 112, 1027-1056.

[2] Austin, D.A. (1999), Politics vs economics: Evidence from municipal annexation, Journal of Urban Economics, 45, 501-532.

[3] Besley, T. and S. Coate (1999), Centralized vs. decentralized provision of local public goods: A political economy analysis, NBER Working paper, 7084 .

[4] Bolton, P. and G. Roland (1996), Distributional conflicts, factor mobility and political integration, American Economic Review, 86, 99-105.

[5] Bolton, P. and G. Roland (1997), The break-up of nations: A political economy analysis, Quarterly Journal of Economics, 112, 1057-1089.

[6] Bolton, P., G. Roland and E. Spolaore (1996), Economic theories of the break-up and integration of nations, European Economic Review, 40, 697705 .

[7] Borck, R. and S. Owings (2003), The political economy of intergovernmental grants, Regional Science and Urban Economics, 33, 139-156.

[8] Calabrese, S., G. Cassidy and D. Epple (2002), Local government fiscal structure and metropolitan consolidation, in: W.G. Gale and J. Rothenberg Pack 
(Eds.), Brookings-Wharton Papers on Urban Affairs, (Brookings Institution Press, Washington, D.C.), 1-32.

[9] Dixit, A. and J. Londregan (1998), Fiscal federalism and redistributive politics, Journal of Public Economics, 68, 153-180.

[10] Ellingsen, T. (1998), Externalities vs internalities: a model of political integration, Journal of Public Economics, 68, 251-268.

[11] Filer, J.E. and L.W. Kenny (1980), Voter reaction to city-county consolidation referenda, Journal of Law and Economics, 23, 179-190.

[12] Gordon, R.H. (1983), An optimal taxation approach to fiscal federalism, Quarterly Journal of Economics, 98, 567-586.

[13] Goyal, S., and K. Staal (2003), The political economy of regionalism, European Economic Review, forthcoming.

[14] Inman, R.P. and D.L. Rubinfeld (1997), Rethinking federalism, Journal of Economic Perspectives, 11(4), 43-64.

[15] Johansson, E. (1999), Intergovernmental grants as tactical instrument: Some empirical evidence from Swedish municipalities, Journal of Public Economics, forthcoming.

[16] Le Breton, M. and S. Weber (2001), The art of making everybody happy: How to prevent a secession?, IMF Staff Papers, forthcoming.

[17] Lockwood, B. (2002), Distributive politics and the costs of centralization, Review of Economic Studies, 69, 313-337.

[18] Oates, W.E. (1972), Fiscal Federalism, Harcourt Brace Jovanovich, New York.

[19] Oates, W.E. (1999), An essay on fiscal federalism, Journal of Economic Literature, 37, 1120-1149.

[20] Persson, T. and G. Tabellini (1996), Federal fiscal constitutions: risk sharing and redistribution, Journal of Political Economy, 104(5), 979-1009. 


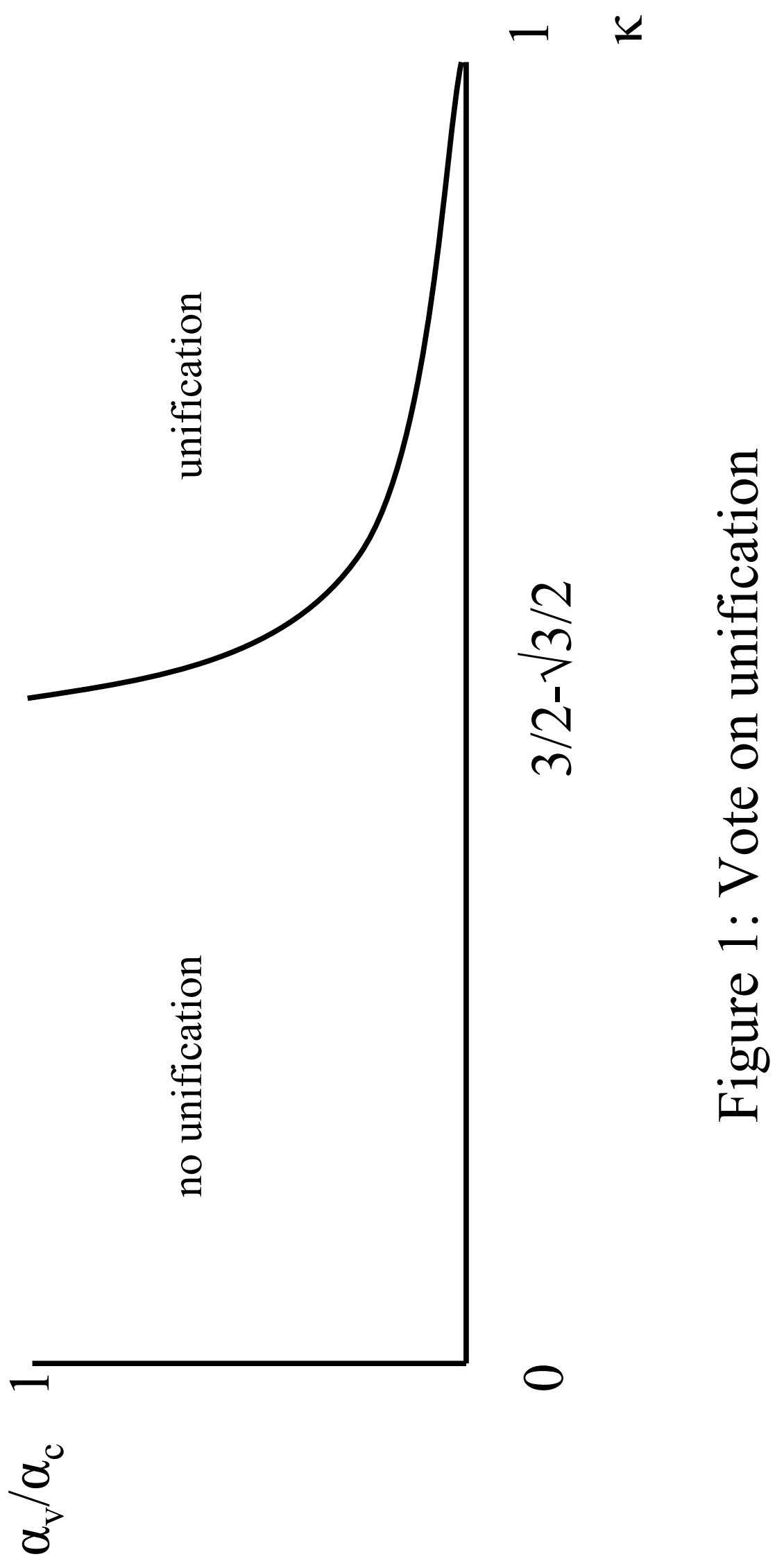




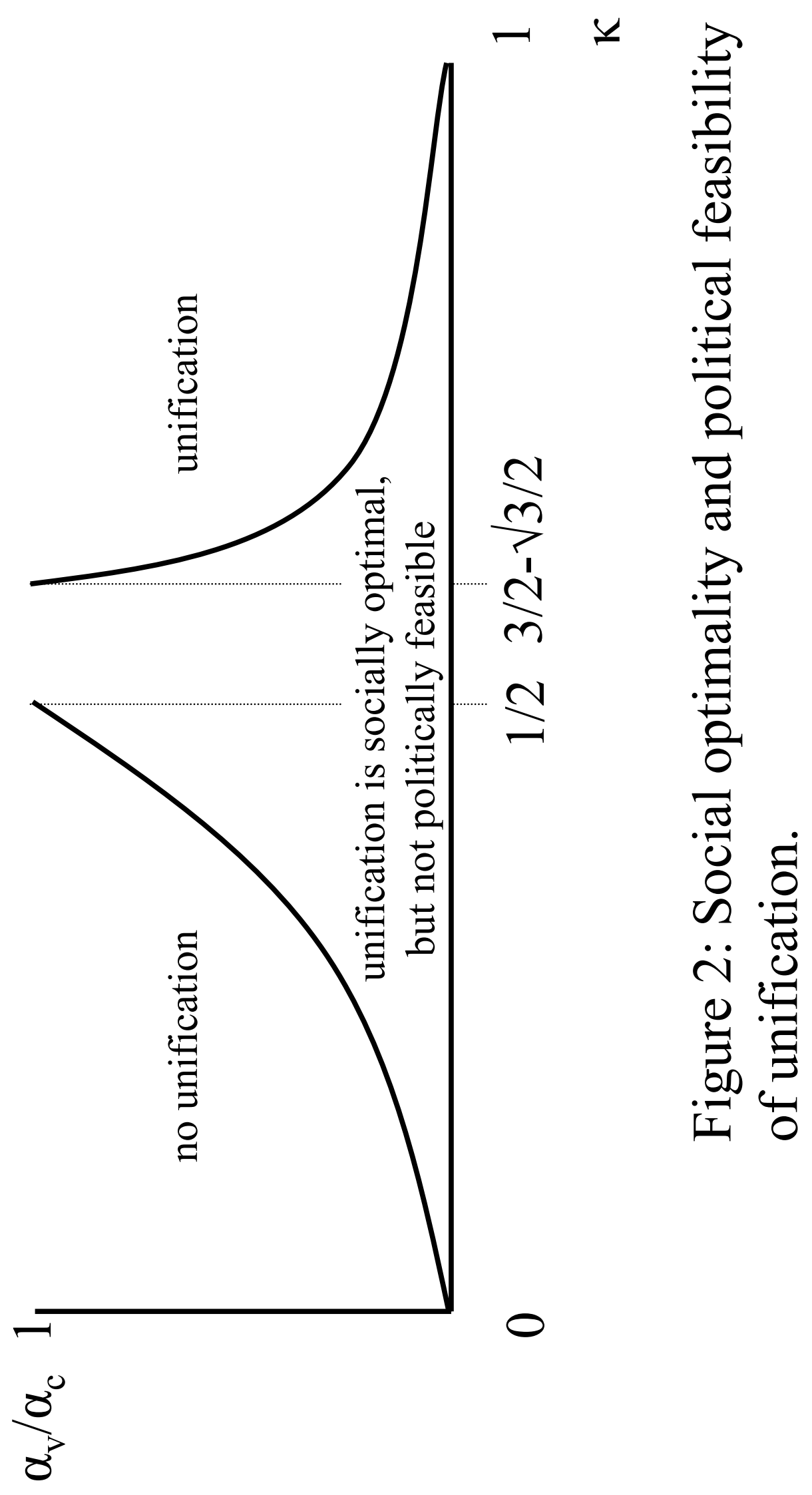

